\section{The Self: Can Behaviorism Inform the Study of The Self?}

\section{Gail Hunter* \\ College of Humanities and Social Sciences, George Mason University, Fairfax, Virginia, USA}

\begin{abstract}
Burrhus Frederic Skinner's discussion of Self-Control begins with the explanation of its implicit nature in establishing relations between stimuli and responses. In functional analysis an independent variable operates as a means of controlling a behavior response for either an analyst or individual. This phenomenon is the focus of experimental science and validating the relational effect is the objective of behaviorist study. Regarding individuals controlling their own behavior their issue of responsibility is of relevance. A major part of adolescent development is learning to take responsibility for his or her self. The learning process coincides with biological, social, and psychological developments that must be navigated with care to avoid negative effects on the individual's self-concept and self-efficacy (belief in one's capacity to function competently). Developing a behavior response repertoire to environmental stimuli is a moment to moment endeavor that Skinner acknowledges but insists on focusing on the behavior and not the behaving individual. By discriminating between stimuli and altering environmental circumstances organisms behave.
\end{abstract}

\section{Review}

The concept of choice and free will are only relevant to Skinner's theory as a means to an end, in that he views individual differences as the direct result of consequential contingencies[1]. Choice and freewill are not useful constructs in the manipulation of environmental stimuli such as removing your hand from a hot stove. The theory presupposes that all behavior responses are based on consequences and distinguishable discriminative stimuli in the individual's environmental experience. Skinner asks what selves are operating in the statement a person knows him or herself[1]. Who is the knower and who is the known? This is an existential contemplation that leads him to question the concept of multiple selves and the integration of those selves. This lends itself to Freud's model of mind and personality [2]. The dimension of purely private events that are beyond even the individual's

*Corresponding author: Gail Hunter,College of Humanities and Social Sciences, George Mason University, Fairfax, Virginia, USA, Tel: 267 4568868; E-mail: ghunter5@gmu.edu

Citation: Hunter G (2019) The Self: Can Behaviorism Inform the Study of The Self?. J Psychiatry Depress Anxiety 5: 021.

Received: April 18, 2019; Accepted: April 29, 2019; Published: May 06, 2019

Copyright: ( 2019 Hunter $\mathrm{G}$. This is an open-access article distributed under the terms of the Creative Commons Attribution License, which permits unrestricted use, distribution, and reproduction in any medium, provided the original author and source are credited. awareness is of no use in Behavior Theory. Only events that are in the individual's awareness can function as operants. Skinner lists various means that individuals employ to guide their behavior in one direction over another. In so doing they are controlling their own behavior to suit their own goals and objectives. Skinner doesn't examine what those objectives are and why they are of importance to the "behaver" except in relation to deprivation and satiation which determine the effectiveness of reinforcement [1].An individual's desires, goals, and objectives are beyond the scope of his model of discriminating stimuli and consequential reinforcement. Once individuals learn the environmental contingencies within their experiential circumstances they set out to arrange the contingencies toward their favor. The social value attached to those contingencies is a matter of importance to the analyst.

How do we define ourselves? Our personal characteristics, political, moral, and religious views; and the roles we play in life serve to answer this question superficially. But our unique awareness, sense of individuality, and integrated experiences provide a more intimate portrait of who we are. Our life work may be to discover and/or cultivate this elusive definition of ourselves. As per Socrates "An unexamined life is not worth living", and Shakespeare's Hamlet "to be or not to be" - that is the question. Adolescents, facing new responsibilities, distinguish themselves as a function of parallel development with social cognition [3].

According to Titchener".....stimuli do something more than arouse sensation; they give rise to processes of a different kind, to "feelings" in a special sense; we do not merely take the impressions as they come, but we are affected by them, we feel them" [4].

The outward display of how we think about ourselves and others is a line of research beginning with self-awareness, self-recognition, and personal agency in infancy. When can babies distinguish themselves from others? What body scheme do they possess and is it present as a psychological primitive (phylogenic innate phenomenon)? When does the temporal concept of extended self-establish the basis of our self-concept? In other words - when do we recognize ourselves as having existed in our past memories. For example, it's fascinating to watch a toddler go away on vacation and come home with fresh memories of being in a faraway place playing and having fun. When they come home you see a more mature child who is grappling with the fact that they remember the vacation time but now they are back home again.Secure attachment and supportive, evaluative, feedback from caretakers factor into a child's sense of self [3].

Skinner's argument that self-awareness in animals and humans alike is the result of reinforcing social contingencies of individual discriminative behavior has since been extended to provide a relational frame interpretation of discrimination in human behavior [5]. Though Skinner denounces mentalisms such as self-development, self-concept, and self-esteem as causes for behavior, research subsequent to his assertions has produced a vast array of literature on the transformational chain of discriminated responses into an emergent self-concept and self-development. Skinner most likely would feel that these 
investigations are a waste of time but we are closer to assisting clients' coping with stressors when we show them how their self-worth and self-efficacy affects their responses to environmental stimuli. The real issue here is that Skinner is not trying to help psychologists help their clients. He is strictly trying to help psychologist change behavior in individuals and society at large. He doesn't claim to be a practitioner or humanistic theorist but his theories do illuminate how the environment can assiduously control behavior.

In Kumru\& Thompson's three tiered model of self-operations the personal, relational, and societal aspects of self-development operate to increase self-awareness, improve other's view of ourselves, and to function authentically in society [6]. To that end we monitor, construe, compare, and appraise ourselves. We determine our self-worth and devise strategies to achieve our goals with self-determination based on our self-efficacy, which is the belief that we can achieve a goal[6].These researchers correlated self-monitoring (changing to fit immediate circumstances) with Marcia's identity statuses and found that identity-achieved adolescents (those who explored and are committed to a career path and a philosophical basis for themselves) have significantly lower self-monitoring behaviors (changing based on situational influences) than diffused (no exploration or commitment), foreclosed (committed without exploring), or moratorium (still exploring or no commitment) status adolescents [7]. This indicates less sensitivity to the opinion of others and a more stable self- presentation and sense of self within the identity-achieved adolescent status group.

In educational settings adolescents are influenced by the achievement levels of their peers and tend to exaggerate their comparisons as much better or much worse than their classmates. This over evaluative response provides an exaggerated self-evaluation and provides a basis for understanding how self-construal is moderated by social comparison in educational settings [8]. Pfeifer et al. took a neurological approach to this aspect of self-development and discovered that neural activity was most activated when adolescent's cognate reflected appraisals (other's opinions) as opposed to their own direct self-appraisals [9]. Using fMRI scans the researchers observed significantly more activity in the medial fronto-parietal network when adolescents considered the perspective of others. In an experiment using fabricated assessments about the importance of professional traits, Eisenstadt et al. compared reaction times and the effects of feedback on adolescent rejected and ideal self-construals (understandings of constructed meaning) [10]. They detected a high occurrence of defense avoidance at faster rate when the subjects judged themselves against unrealistic traits that they themselves felt they did not match. This indicates a self-protective function against environmental feedback.

Swann et al. purports the essentiality of self-views and the importance of developing and implementing theoretically informed programs that aim to improve them [11].

To quote William James, in Principles of Psychology"Personality implies the incessant presence of two elements, an objective person known by a passing subjective thought and recognized as continuing in time" [12].

Modell delineates the conception of "self" as structure vs. consciousness, presenting arguments of theorists and researchers who support both concepts [13]. First, Modell attempts to observe and describe private events (private experience) from an outsider's viewpoint. With full awareness of the interconnected unconscious processes and conscious experience, Sigmund Freud and William James are the primary theorists set up with these seemingly opposing views of structure and phenomenology of consciousness [13]. The research method introspection is a function of the fluid self-conscious and James' term stream of consciousness - is in fact - the self. Another aspect to be considered here is the stable (not fluid) entity known as core identity - which some view as an almost biological entity serving as a recognizable and retrievable essence regardless of situational conditions [13].

According to Modell, Freud purports the objective concept of ego as opposed to the unscientific subjective self-experience $[2,13]$. This stands as the ongoing dilemma of placing the ego in an impersonal schema devoid of uniqueness and individuality. I would not go so far in my review of Freud's ego theory [2]. For it is the work of the therapist to extract individual uniqueness through Freud's structure of the mind or personality model [2]. I also support James' phenomenological, philosophical identification of consciousness and the self. Through my studies I find myself able to synthesize philosophical dualities. I recognize that we can only understand what is presented in dualism (two seemingly opposed theories). Presenting what something is in terms of what it is not may be the consequences of our right brain left brain neuro-structure [3].

Continuing, Modell points out that there is a school of thought that doubts the validity of the self-concept from either perspective [13]. One such notable is David Hume, who argues that if the concept of self is contingent upon self-awareness then it may be only a fantasy which Skinner would call a mentalism [1]. Hume believed that unrelated, fleeting, and unfettered thoughts are evidence that there is no continuity which can be called a "self". However, the field of psychopathology has presented formidable evidence that the loss of a sense of self, the feeling that one has no self or that it has been devoured by someone else is a devastating, catastrophic psychological state known as "annihilation anxiety" [13].

Just as the nervous system is comprised of the central and the autonomic nervous systems, and the autonomic is comprised of the sympathetic and parasympathetic the continuing self and consciousness of self-work together to allow humans to interact with and respond to environmental stimuli while maintaining a central identity [3]. Consciousness of self is modified by affirming and negating environmental stimuli (Skinner's concept of reinforcement). Feedback from others sometimes operates outside of our awareness but none-the less impacts our state self-esteem (how good we feel about ourselves in the current emotional context) [14]. Park et al. investigated the effects of negative interpersonal feedback [14]. The researchers were able to correlate self-presentation goals and goal pursuits/actions with affect and state self-esteem (mood and situational feelings about our self). In their adolescent sample they found some subjects based their selfworth on others approval to a greater extent than did others. And those with high self-esteem valued themselves as warm and caring, whereas subjects with low self-esteem valued physical attractiveness to a greater degree. In another study, Sealey listened to tape-recordings of a sample of 8 to 11 year olds which revealed what he termed three dimensions of Freud's id in three aspects of the social self. They are the immediate actor, the individual self, and the self in wider social relations $[2,15]$.

Ecclesexplored personal-identity-related processes and applied these ideas to gender collective identities and behavioral choices16]. 
Who am I? Questions like this we ask ourselves in an effort to create a foundation for the psychological aspect of identity, especially during adolescence. Eccles summarized an expectancy value perspective on this aspect of human psychology focusing on how personal and collective identities impact motivated action and expectations of successful outcomes toward uniqueness and its subsequent satisfaction [16]. Defining these aspects of one's identity as what is most personally valued by the ME self, the self-one comes to know by observing one's own behaviors, the author contrasts this ME self against collective identities, - the WE-self, which consists of gender, race, religion,social class, culture, and family. A positive correlation between essentiality to the individual and motivation to enact behaviors that sustain these connections was evidenced.

Using these longitudinal methods, the Socio Cultural expectancy/ value model: motivated behavioral choices, was validated. Activity/ task pleasure is highest for activities providing a challenge and an opportunity for mastery. Moderately difficult activities of achievable tasks will yield the greatest variance in expectancy related concepts of self and task value subjectivity. This concept would make an interesting correlation with reinforcement schedules. It may be that the most effective schedules correlate with the expectancy/value model and the associated self-concepts.

All of the researchers included in this paper chose to explore ideas that Skinner would have labeled fictions and mentalisms. Though he recognizes that self-awareness is created by social contingencies that reinforce discrimination, he rejects the importance of self in subsequent operant relations [17]. This causes a huge chasm in psychology that has been creatively bridged by innovative theorist and researchers bringing forth important developments in the area of depression therapy and personality theory.Self-discrimination implies self-awareness which has been extensively, empirically studied [17]. This extends the behavior analytic conception of self-awareness to address maladaptive environmental transactions which according to Ferster and Lewinsohn's, 1973 model lead to symptoms of depression [17]. The behavioral analytic treatment of acute major depression and the prevention of a relapse within two years was found to outperform cognitive behavioral therapy in the Jacobson and Gortner, 2000 study, as cited in Barnes [17]. The behavioral analytic approach was based on increased activities that provide access to rewarding, pleasurable and mastery experiences and reduced aversive control.

Who is controlling who? Is there one entity or more than one? Technology has answered this question recently according to Gaia. com 2018. Consciousness does not originate in our body. It is separate energy that coexists within our body individually and collectively. Skinner seems to accept Freud's theory of mind/personality (id/reinforced basic drives, ego/mediating environmental exigencies, and superego/sense of morality). However, he emphatically denounces the self as the cause and originator of behavior, instead turning to the environment for influences that usually go unnoticed. He simply states that the concept of self is not necessary for the analysis of behavior and blames the convenience of "personification" for our perpetual reliance on the self as responsible for human behavior [1].

Skinner acknowledges the "inner determiner" as a self/personality and that these "selves" are often in conflict with each other. The internal duality/multiplicity begs the questions - are they aware of each other, and which is in control at any given time ? "The self is most commonly used as a hypothetical cause of action" [1]. Skinner states that we create the idea of a self-due to anxiety about unexplained phenomena such as - who is controlling whom in the actions of self-control and self-knowledge? Skinner continues with the statement that "the self is an organized system of responses". An explanation of a functionally unified system includes the concept of contextual personality brought about by discriminative stimuli. In order to achieve particular reinforcement a common mode of action is employed. Skinner states that we may be composed of various types dwelling within us and deploying contingent upon the available reinforcements. This sounds as if we are all born with the same capacity to possess any personality and perform any type of behaviors that our environment reinforces. There are no individual traits or talents, virtues or propensities just pure learned responses. Even if this were absolutely true it wouldn't logically follow that there is no entity known as the self. Twin studies reveal that regardless of environment the two end up with similar professions and lifestyles. It is possible that the two environments provided the same reinforcements and thus the same responses for the twins [18]. But that indicates that there was a self there upon which the environment acted.And twins raised in the same physical environment respond differently to reinforcements within that environment because there are other aspects involved (such as gene-environment correlations) that individualize the experience for each of the twins $[18,19]$.

\section{Conclusion}

Since the beginning of the twentieth century the study of human behavior has been of great interest to psychologists [20]. After experimenting with animal learning the objective study of behavior was in direct opposition to introspection. By 1912 this new methodology was based on Thorndike and Pavlovian conditioning [20]. During the 1950s, Skinner called for strict epistemological objectiveness without the mentalist concept of consciousness. This perspective was prevalent in the US until increased interest in Chomskian psycholinguistics ushered in a new era at the end of the 1960s [20]. Behaviorism is still applied to practical situations and directly applied in the treatment of autism. Throughout the relatively brief history of behaviorism it has contributed very little to the understanding of mentalistic conceptions such as the self as a psychological entity [20,21]. However, with increased interest in Positive Psychology since the beginning of the 21st century researchers will gain new insight into how behaviorism and cognitive behaviorism support the development and maintenance of a healthy self.

\section{References}

1. Skinner BF (1953) Science and human behavior. The Free Press, New York, NY.

2. Freud S (1930) Civilization and its discontents. Martino Publishing, Mansfield Centre, CT.

3. Shaffer DR, Kipp K (2010) Developmental psychology: Childhood and adolescence.Wadsworth Cengage Learning.

4. Barrett LF, Bliss-Moreau E (2009) Affect as a psychological primitive. AdvExpSocPsychol 41: 167-218.

5. Roche B, Barnes D (1997) A transformation of respondently conditioned stimulus function in accordance with arbitrarily applicable relations. J Exp Anal Behav 67: 275-300.

6. Kumru A, Thompson RA (2003) Ego identity status and self-monitoring behavior in adolescents. J Adolesc Res 18: 481-495. 
7. Marcia JE (1966) Development and validation of ego-identity status. J Person SocPsychol 3: 551-558.

8. Cheng R, Lam S (2007) Self-construal and social comparison effects. Br JEduPsychol 77: 197-211.

9. Pfeifer JH, Masten CL, Borofsky LA, Dapretto M, Fuligni AJ, et al. (2009) Neural correlates of direct and reflected self-appraisals in adolescents and adults: When social perspective-taking informs self-perception. Child Dev 80: 1016-1038.

10. Eisenstadt D, Leippe MR, Rivers JA (2002) Asymmetry and defense in self-comparison: Differential reactions to feedback about the rejected and ideal selves. Self Identity 1: 289-311.

11. Swann WBJ, Chang-Schneider C, Larsen McClarty K (2007) Do people's self-views matter? self-concept and self-esteem in everyday life. Am Psycholog 62: 84-94.

12. Wozniak RH (1999) Classics in psychology. Historical essays. Thoemmes Press, Bristol, UK: 1855-1914.

13. Modell AH (1993) The private self. Harvard University Press, Cambridge, MA.

14. Park LE, Crocker J (2008) Contingencies of self-worth and responses to negative interpersonal feedback. Self Identity 7: 184-203.
15. Sealey A (1996) "Who do you think you are?": Four children's sociolinguistic strategies in the negotiation of self. CurrIss Lang Society 3: 22-35.

16. Eccles J (2009) Who am I and what am I going to do with my life? personal and collective identities as motivators of action. EducatPsycholog 44: 78-89.

17. Dymond S, Barnes D (1997) Behavior-Analytic Approaches to Self-Awareness. The PsychologRecord 47: 181-200.

18. Klahr AM, Thomas KM, Hopwood CJ, Klump KL, Burt SA (2013) Evocative gene-environment correlation in the mother-child relationship: A twin study of interpersonal processes. Develop Psychopathol 25: 105-118.

19. Baum W (1994) Understanding behavior: Behavior, culture, and evolution (3rd ed.). Wiley Publishing, Hoboken, NJ.

20. Parot F (2001) History of behaviorism. The encyclopedia of the social and behavioral sciences. Center for Advanced Study in the Behavioral Sciences, Stanford, CA, USA: 1131-1137.

21. Robinson MD, Barrett LF (2010) Belief and feeling in self-reports of emotion: Evidence for semantic infusion based on self-esteem. Self Identity 9: 87-111. 


\section{Hit}

Journal of Anesthesia \& Clinical Care

Journal of Addiction \& Addictive Disorders

Advances in Microbiology Research

Advances in Industrial Biotechnology

Journal of Agronomy \& Agricultural Science

Journal of AIDS Clinical Research \& STDs

Journal of Alcoholism, Drug Abuse \& Substance Dependence

Journal of Allergy Disorders \& Therapy

Journal of Alternative, Complementary \& Integrative Medicine

Journal of Alzheimer's \& Neurodegenerative Diseases

Journal of Angiology \& Vascular Surgery

Journal of Animal Research \& Veterinary Science

Archives of Zoological Studies

Archives of Urology

Journal of Atmospheric \& Earth-Sciences

Journal of Aquaculture \& Fisheries

Journal of Biotech Research \& Biochemistry

Journal of Brain \& Neuroscience Research

Journal of Cancer Biology \& Treatment

Journal of Cardiology: Study \& Research

Journal of Cell Biology \& Cell Metabolism

Journal of Clinical Dermatology \& Therapy

Journal of Clinical Immunology \& Immunotherapy

Journal of Clinical Studies \& Medical Case Reports

Journal of Community Medicine \& Public Health Care

Current Trends: Medical \& Biological Engineering

Journal of Cytology \& Tissue Biology

Journal of Dentistry: Oral Health \& Cosmesis

Journal of Diabetes \& Metabolic Disorders

Journal of Dairy Research \& Technology

Journal of Emergency Medicine Trauma \& Surgical Care

Journal of Environmental Science: Current Research

Journal of Food Science \& Nutrition

Journal of Forensic, Legal \& Investigative Sciences

Journal of Gastroenterology \& Hepatology Research

Journal of Gerontology \& Geriatric Medicine
Journal of Genetics \& Genomic Sciences

Journal of Hematology, Blood Transfusion \& Disorders

Journal of Human Endocrinology

Journal of Hospice \& Palliative Medical Care

Journal of Internal Medicine \& Primary Healthcare

Journal of Infectious \& Non Infectious Diseases

Journal of Light \& Laser: Current Trends

Journal of Modern Chemical Sciences

Journal of Medicine: Study \& Research

Journal of Nanotechnology: Nanomedicine \& Nanobiotechnology

Journal of Neonatology \& Clinical Pediatrics

Journal of Nephrology \& Renal Therapy

Journal of Non Invasive Vascular Investigation

Journal of Nuclear Medicine, Radiology \& Radiation Therapy

Journal of Obesity \& Weight Loss

Journal of Orthopedic Research \& Physiotherapy

Journal of Otolaryngology, Head \& Neck Surgery

Journal of Protein Research \& Bioinformatics

Journal of Pathology Clinical \& Medical Research

Journal of Pharmacology, Pharmaceutics \& Pharmacovigilance

Journal of Physical Medicine, Rehabilitation \& Disabilities

Journal of Plant Science: Current Research

Journal of Psychiatry, Depression \& Anxiety

Journal of Pulmonary Medicine \& Respiratory Research

Journal of Practical \& Professional Nursing

Journal of Reproductive Medicine, Gynaecology \& Obstetrics

Journal of Stem Cells Research, Development \& Therapy

Journal of Surgery: Current Trends \& Innovations

Journal of Toxicology: Current Research

Journal of Translational Science and Research

Trends in Anatomy \& Physiology

Journal of Vaccines Research \& Vaccination

Journal of Virology \& Antivirals

Archives of Surgery and Surgical Education

Sports Medicine and Injury Care Journal

International Journal of Case Reports and Therapeutic Studies

Submit Your Manuscript: http://www.heraldopenaccess.us/Online-Submission.php 